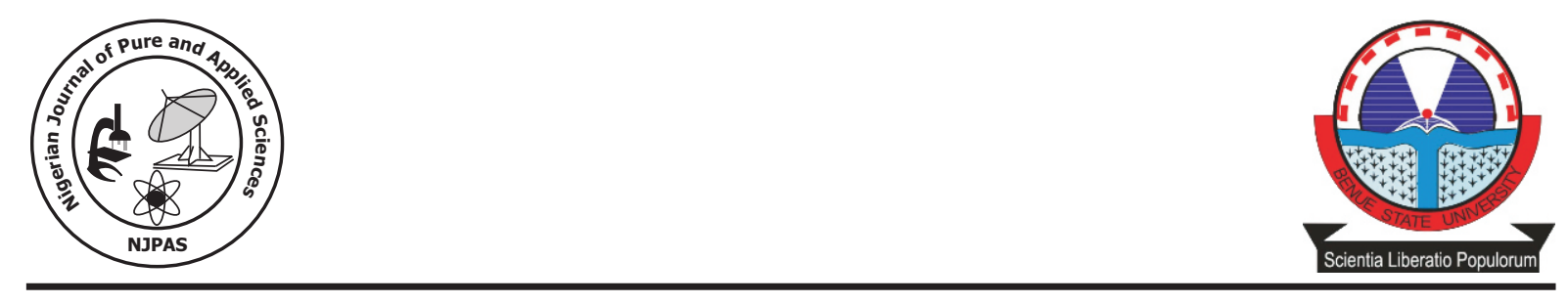

\title{
Thermodynamic and Kinetic Parameters of Methanolic Extract of Leaves of Cochlospermum Tinctorium as Eco-friendly Inhibitor for Corrosion of Mild Steel in HCL Medium
}

\author{
Adams, G. I. ${ }^{1}$, Adejo, S. ${ }^{1 *}$., Ahile, J. U ${ }^{1}$. Gbertyo, J. A ${ }^{1}$. and Ogbodo, J. $\mathrm{O}^{2}$. \\ ${ }^{1}$ Department of Chemistry, Benue State University, Makurdi, Nigeria \\ ${ }^{2}$ Benue State Polytechnic, Ugbokolo, Benue State, Nigeria \\ * Author for Correspondence: sadejo@bsum.edu.ng
}

\begin{abstract}
Thermodynamic, kinetic and adsorptive parameters of methanolic extract of leaves of Cochlospermum tinctorium as eco-friendly inhibitor for the corrosion of mild steel in $\mathrm{HCl}$ medium were evaluated through the weight loss method at $303 \mathrm{~K}$ and $311 \mathrm{~K}$. The inhibition efficiency, \%IE, increased with increase in extract concentration, but found to be better at $303 \mathrm{~K}$ than $311 \mathrm{~K}$. The decrease in \%IE with increase in temperature with the average value of $81.88 \mathrm{~kJ} / \mathrm{mol}$ for activation energy, $\mathrm{E}_{\mathrm{a}}$, and the values of free energy, $\Delta G$, for the adsorption process are all supportive of physical adsorption mechanism. The values of heat of adsorption, $\mathrm{Q}_{\mathrm{ads}, \text {, }}$ are all negative, an indication that the adsorption process was exothermal. The half-life, $\mathrm{t}_{1 / 2}$, value increased with increase in inhibitor concentration and low at high higher, implying the inhibitor performance increased with increase in the extract concentration and decreased with rise in temperature. The data best fitted the Langmuir adsorption isotherm.
\end{abstract}

Key Words: Cochlospermum tinctorium, eco-friendly inhibitor, thermodynamic parameter, half-life, adsorption isotherm.

\section{Introduction}

Humanity has now come to terms with the repercussions and the environmental accidents that our behaviour has impacted on the earth, putting it in a compromising future. Chemical weapons, pesticides, fertilizers, industrial effluents, paints and organic solvents have changed the health of plants and world inhabitants to the point of contaminating even the most remote places on the planet (Hodgeset al., 2010). As a result, man at the moment is environmentally conscious, trying to be prudent and transparent in the use of chemicals. This has resulted in the search for eco-friendly chemicals within the scientific and engineering circles. The focus on plant extracts, away from synthetic inhibitors, as eco-friendly inhibitors for metal corrosion prevention is due mainly to economic reasons, strict environmental regulations, renewability and biodegradability (Arora et al., 2007; Selviet al., 2009, Alaneme and Olusegun, 2012). The extracts such natural substances contain mixtures of compounds having oxygen, nitrogen, sulphur and phosphorus which help in corrosion inhibition process (Jai and Ali, 2008). The inhibition efficiency of the compounds containing these elements in their structures as corrosion inhibitors can be attributed to the number of mobile electron pairs present, the orbital character of free 
electrons and electron around the atoms (Arora et al., 2007). Quite a number of extracts from plants have been investigated (Avwiri and Igho, 2003; El-Etre, 2003; Orubite and Oforka, 2003; Benabdellah et al, 2006; Oguzie, 2006; Eddy et al., 2008; Eddy and Ebenso, 2008; Adejo et al., 2010, Nnanna etal., 2012, Adejo et al., 2013).

Cochlospermeae is a well-known plant family in herbal medicine. The species Cochlospermum tinctorium, the plant of interest in this work, is a widely distributed plant within the savanna areas of West and Central Africa (Etuket al., 2009). This plant is called balagarde in Hausa, abanzi in Igbo, cewatu in Yoruba, ukpatafulo in Idoma and kpavande in Tiv, all these being the tribes in Nigeria, signifying the importance of the plant in the country. In Mali and Ivory Coast the plant is widely used for the treatment of jaundice, malaria, abdominal pain, wound healing, haemorrhoids, intestinal worms, bilharizias and hepatitis (Togolaet al., 2005). Nergard et al., (2005) has shown that pectic polysaccharides obtained from the plant are responsible for its bioactivities.

In this study, methanol extract of leaves of the plant was put into a different use; as inhibitor of corrosion of mild steel in $\mathrm{HCl}$ solution. The thermodynamic, kinetic and adsorptive parameters of the inhibition process were evaluated at two temperatures of 303 Kand311 K, a narrow temperature range employed to maintain the molecular structure(s) of the component(s) responsible for the inhibition process in the course of the experiment.

\section{Materials and Method Material preparations}

A sample of mild steel of composition (\%W); Mn(0.56), P (0.04), C(0.27), Si(0.25), $\mathrm{S}(0.04)$ with rest being $\mathrm{Fe}$, was obtained from Department of Mechanical Engineering, University of Agriculture, Makurdi-Nigeria. Coupons of the dimension of $2 \mathrm{~cm} \mathrm{x} 2 \mathrm{~cm} \mathrm{x}$ $0.13 \mathrm{~cm}$ (with a $2.5 \mathrm{~mm}$ hole drilled through an edge of each) were prepared as described in
Eddy and Ebenso (2008).

Leaves of the plant were shade-dried, ground and $20 \mathrm{~g}$ soaked in $200 \mathrm{ml}$ of absolute methanol in a $250 \mathrm{ml}$ volumetric flask, which was properly corked and kept, with occasional shaking, for 48 hours. The extract obtained, therefrom, was filtered and the methanol was carefully evaporated at $321 \mathrm{~K}$, to available any possible structural changes to any component of the extract, using Clifton Model thermostated water bath. Stock solutions of the extract of the concentrations of $0.1,0.2$, $0.3,0.4$ and $0.5 \mathrm{~g} / \mathrm{dm}^{3}$ were prepared in $2 \mathrm{M}$ $\mathrm{HCl}$. Analytical grade reagents were all used, with double distilled used for all solution preparations.

\section{Method}

The Weight loss measurement was carried out as reported in Orubite-Okorosaye and Oforka (2004) at 303 Kand $311 \mathrm{~K}$ in the thermostated water bath. The first part of the experiment involved weighing the coupon using ae Adam AFP weighing balance (4100 Model) and suspending it in a beaker containing the corrodant, which was a $100 \mathrm{ml}$ of the acid in $250 \mathrm{ml}$ beaker, using a thread passed through the hole to tie it to a retort stand. The coupon was retrieved from the solution at an interval of 2 hours for 12 hours. The procedure was repeated using solution of different concentrations of the extract introduced into the corrodant. At retrieval, each coupon was dipped immediately into a saturated ammonium acetate solution at room temperature to terminate the reaction, washed with distilled water and then dried in acetone, kept in a desiccator to reach ambient temperature and carefully re-weighed. The weight loss was calculated using the expression,

$W=\left(W_{i}-W_{f}\right)$

where $\mathrm{W}$ is weight loss of coupon, $\mathrm{W}_{\mathrm{i}}$ is the weight before immersion and $\mathrm{W}_{\mathrm{f}}$ the final weight of the coupon after retrieval.

The inhibition efficiency, $\% I E$, and degree of surface coverage, $\theta$, were calculated 
by the use of equations (2) and (3), inhibitor onto the surface of the metal (Siakaet respectively. al., 2012).

$$
\begin{aligned}
& \% I E=\left(1-\frac{W_{1}}{W_{2}}\right) \times 100 \\
& \theta=1-\frac{W_{1}}{W_{2}}
\end{aligned}
$$

where $W_{l}$ and $W_{2}$ are weight losses of the coupon in the presence and absence of inhibitor, respectively, at the same temperature.

The corrosion rate, $\mathrm{CR}$, of the mild steel was obtained using the NACE (1984) formula (equation 4) (Orubite-Okorosaye and Oforka, 2004).

$$
\mid C R_{(m d d)}=\frac{534 \mathrm{~W}}{D A T}
$$

where $W$ is weight loss (mg), $\mathrm{D}$ the density of the mild steel $\left(\mathrm{g} / \mathrm{cm}^{3}\right)$, A the surface area of the coupon in $\mathrm{cm}^{2}$ and $\mathrm{T}$ the exposure time in hours and $\mathrm{mdd}$ is $\mathrm{mg} / \mathrm{dm} /$ day.

\section{Results and Discussion}

\section{Effect of the concentration and temperature}

The extract has inhibitive effect on the corrosion of mild steel in $\mathrm{HCl}$ medium as it can clearly be seen from Table 1 that the corrosion rate decreases and IE\% increases with increase in the extract concentration at the two temperatures. However, the inhibitor performance is higher at the lower temperature, suggestive of physical adsorption mechanism for adsorption of the

\section{Thermodynamic parameters}

The activation energy, $E_{a}$, of the corrosion process was evaluated by the used of Arrhenius equation (equation 5) (Atkins, 1982; Eddy et al., 2008).

$$
C R=A \exp ^{\left(\frac{E_{a}}{R T}\right)}(5)
$$

where $C R$ is corrosion rate, $A$ the Arrhenius parameter, $E_{a}$ the activation energy of the corrosion reaction, $R$ the gas constant and $T$ the temperature in Kelvin. A linearised form of equation (5) is given thus;

$\log C R=\log A-\frac{E_{a}}{2.303 R T}$ (6)

For corrosion rates at two temperatures $\left(T_{1}\right.$ and $T_{2}$ ) the expression below is obtained from equation(6).

$$
\frac{\log C R_{2}}{C R_{1}}=\frac{E_{a}}{2.303 R\left[\frac{1}{T_{1}}-\frac{1}{T_{2}}\right]}
$$

Corrosion rates were evaluated at $303 \mathrm{~K}$ and $311 \mathrm{~K}$. In spite of the closeness of the temperatures it was found there exist a significant difference in the corrosion rate between the two temperatures. Calculated corrosion rate and inhibition efficiency at the

\begin{tabular}{|c|c|c|c|c|}
\hline \multirow[t]{2}{*}{$\begin{array}{l}\text { Conc. } \\
\text { (g/L) }\end{array}$} & \multicolumn{2}{|c|}{$\begin{array}{l}\text { CR } \\
\text { (mdd) }\end{array}$} & \multicolumn{2}{|l|}{$\% \mathrm{IE}$} \\
\hline & $303 \mathrm{~K}$ & $313 \mathrm{~K}$ & $303 \mathrm{~K}$ & $311 \mathrm{~K}$ \\
\hline Blank & 0.3872 & 0.7010 & - & - \\
\hline 0.1 & 0.1561 & 0.4798 & 59.68 & 31.55 \\
\hline 0.2 & 0.1499 & 0.3966 & 61.29 & 43.42 \\
\hline 0.3 & 0.1374 & 0.3256 & 64.51 & 53.55 \\
\hline 0.4 & 0.1124 & 0.3053 & 70.97 & 56.44 \\
\hline 0.5 & 0.1062 & 0.2789 & 72.57 & 60.21 \\
\hline
\end{tabular}
two temperatures are shown in Table 1, while Table 2 shows the values of activation, heat of adsorption, free energy and half-life for the corrosion process. 
Table 2. Evaluated Values of Activation Energy ( $\left.E_{a}\right)$, Heat of Adsorption $\left(Q_{a d s}\right)$, Free Energy $\left(\Delta G_{a d s}\right)$ and Half-life $\left(\mathrm{t}_{1 / 2}\right)$ for the Inhibition Process.

\begin{tabular}{lcccccc}
\hline $\begin{array}{l}\text { Conc } \\
\left(\mathrm{g} / \mathrm{dm}^{3}\right)\end{array}$ & $\begin{array}{c}E_{a} \\
(\mathrm{~kJ} / \mathrm{mol})\end{array}$ & $\begin{array}{c}-Q_{a d s} \\
(\mathrm{~kJ} / \mathrm{mol})\end{array}$ & \multicolumn{3}{c}{$\begin{array}{c}-\Delta G_{a d s} \\
(\mathrm{~kJ} / \mathrm{mol})\end{array}$} & \multicolumn{2}{c}{$\begin{array}{c}\text { t//2 } \\
\text { (h) }\end{array}$} \\
\hline Blank & 49.36 & - & - & - & - & - \\
0.1 & 93.37 & 114.28 & 16.91 & 14.02 & 35.02 & 7.39 \\
0.2 & 80.91 & 70.95 & 15.33 & 13.86 & 34.67 & 9.63 \\
0.3 & 71.74 & 44.59 & 14.66 & 13.87 & 40.08 & 11.73 \\
0.4 & 83.09 & 62.19 & 14.68 & 13.43 & 44.73 & 11.91 \\
0.5 & 80.29 & 54.72 & 14.32 & 13.25 & 49.17 & 14.88 \\
\hline
\end{tabular}

The value of Ea was found to be higher in the presence of the extract than pure corrodant. $E_{a}$ values in the presence of the inhibitor ranged from 71.74 to $93.37 \mathrm{~kJ} / \mathrm{mol}$. The values of $E_{a}$ are close to $80 \mathrm{~kJ} / \mathrm{mol}$, the threshold value for physical adsorption mechanism, which is clearly supportive of physical adsorption mechanism (Eddy et al., 2008).

$$
Q_{a d}=\frac{2.303 R\left[\log \left(\frac{Q_{2}}{1-Q_{2}}\right)-\log \left(\frac{Q_{1}}{1-Q_{1}}\right)\right] T_{2 T_{1}}}{T_{2}-T_{1}}
$$

Free energy values for the adsorption process were evaluated by the use of expression;

$$
\Delta \overline{G_{a d s}}=-2.303 \operatorname{Tog}(55.5 \mathrm{~K})
$$

$$
\text { where } \quad K=\frac{\theta}{(1-\theta)[c]}
$$

$\mathrm{C}$ is the concentration of the extract and 55.5 is concentration of water expressed in moles (i.e. $\sim 1000 \mathrm{~g} / \mathrm{dm}^{3}$ ) (Bastidas et al., 2005).

Calculated values of $\Delta G_{a d s}$ are all negative, an indication of spontaneity of adsorption process. However, $\Delta G_{a d s}$ values are more negative at $303 \mathrm{~K}$ than $311 \mathrm{~K}$, implying that the spontaneity of the adsorption process and hence the stability of the adsorbed layer of the inhibitor is higher at lower temperature (Atkins, 1982).

\section{Kinetic Consideration}

Studies have shown that the corrosion reaction of metals is of first-order kinetics (Okafor et al., 2010; Nair et al., 2010) and therefore first-order equations were employed. Values of the half-life, $t_{1 / 2}$ in hours for the corrosion process in presence of the inhibitor were evaluated by the use of equation (10) (Atkins, 1982; Onen and
$Q_{a d s}$ values evaluated through equation (8) are all negative (average $=-87.01 \mathrm{~kJ} / \mathrm{mol}$ ), an evidence of exothermic process for the adsorption of this extract onto the mild steel surface. These values are large suggesting that the heat of adsorption for the process was quite large. The negative values also show that the adsorption and hence the efficiency of the inhibitor will decrease with increase in temperature (Eddy and Ebenso, 2008).

Nwufo, 2010

$$
t_{\frac{1}{2}}=\frac{0.693}{k}
$$

where $k$ is the rate constant for the corrosion reaction, which was obtained by the use of the integrated rate equation for first-order reaction (equation 11).

$$
\ln A_{t}=\ln A_{o}-k t
$$

$A_{o}$ is the initial weight of the steel sample and $A_{t}$ is the weight left after the corrosion reaction. The $t_{1 / 2}$ was found to increase with increase in the inhibitor concentration (Table 2 ), implying a decrease in $k$ with increase in the concentration. This means that the inhibition process increased with the concentration of the inhibitor. Values of $t_{1 / 2}$ were found to be higher at $303 \mathrm{~K}$ than at 311 $\mathrm{K}$, indicative of the fact that the corrosion reaction increased at the higher temperature, 
another evidence in support of physical adsorption mechanism as earlier stated.

\section{Adsorption Consideration}

Common adsorption isotherms frequently used in trying to understand the mechanism of inhibition of corrosion reactions are the Langmuir, Frumkin, Freundlich, Temkin, Flory-Huggins, ElAwady and Bockris-Swinkels. A general equation to represent these isotherms is given by equation (12) (Eddy et al., 2008).

$$
f(\theta, x) \exp ^{-2 \otimes \theta}=K C
$$

where $f(\theta, x)$ is configuration factor that is dependent upon the physical model and the assumption underlying the derivation of the isotherm, $\theta$ the degree of surface coverage, $C$ the concentration of inhibitor in the electrolyte, $\mathrm{x}$ is the size ratio,

$$
\begin{aligned}
& \frac{C}{\theta}=\frac{1}{K}+C \\
& \log \theta \quad=\quad \log K_{F}+\frac{1}{n_{F}} \log C \\
& \log \theta \frac{\theta}{(1-\theta) C}=\log K+\frac{2 \alpha \theta}{2.303}(15) \\
& \log \theta \frac{(\theta)}{1-\theta}=\log K^{\prime}+y \log C(16)
\end{aligned}
$$

Table 3: Values parameters for adsorption isotherms

\begin{tabular}{llll}
\hline Isotherm & & $303 \mathrm{~K}$ & $311 \mathrm{~K}$ \\
\hline Langmuir & $\mathrm{R}^{2}$ & 0.9931 & 0.9973 \\
& $\mathrm{~K}$ & 17.1527 & 5.1840 \\
Freundlich & $\mathrm{R}^{2}$ & 0.8667 & 0.9811 \\
& $\mathrm{n}_{\mathrm{F}}$ & 0.7853 & 2.4444 \\
& $\mathrm{~K}_{\mathrm{F}}$ & 0.0819 & 0.8287 \\
Frumkin & $\mathrm{R}^{2}$ & 0.6403 & 0.8150 \\
& $\alpha$ & -2.8589 & -2.5385 \\
El-Awady & $\mathrm{K}$ & $3.2 \times 10^{5}$ & 55.6929 \\
& $\mathrm{R}^{2}$ & 0.8441 & 0.9904 \\
& $\mathrm{y}$ & 0.3744 & 0.7507 \\
& $\mathrm{~K}$ & 22.5595 & 3.6164 \\
\hline
\end{tabular}

The adsorptive parameters obtained from the isotherm plots given in Table 3. From the coefficient of determination, $R^{2}$, values it is evidently clear that the Langmuir isotherm is most applicable model for the adsorption of this extract onto the mild steel surface, while Freundlich and El-Awady are applicable at $311 \mathrm{~K}$.

The adherence of the adsorption to the Langmuir isotherm has been argued by Orubite-Okorosaye and Oforka (2004) to signify that the extract covered both the anodic and cathodic sites on the metal surface. The argument is quite plausible considering the fact that Langmuir isotherm involves monolayer over the entire surface. The positive value of $K$ signifies favourable adsorption, and judging from the values at the two temperatures, the adsorption process was more favourable at the lower temperature.

The parameter $n_{F}$ in the Freundlich isotherm is related to intensity of adsorption and it varies with heterogeneity of the material (Chatterjeeet al, 2009). The values of Freundlich isotherm constants $n_{F}$ and $K_{F}$ obtained are 0.7853 and 2.4444 and 0.0819 and 0.8287 at $303 \mathrm{~K}$ and $311 \mathrm{~K}$, respectively. $\mathrm{n}_{\mathrm{F}}$ values are within the normal beneficial adsorption of between 1 and 10 (Adejo et al., 2008), but higher at higher temperature with even a better $\mathrm{R}^{2}$. This is, however, in invariance with the observation in the case of Langmuir. According to Khadom et al (2010), typical value of $n_{F}$ is 0.6 , which implies that this adsorptionprocess cannot be reasonably 
The negative sign of ain Frumkin isotherm signifies existence of molecular interaction within the adsorbed layer. The $\mathrm{R}^{2}$ are relatively low, and therefore, this adsorption cannot also be reasonably modeled by the isotherm. The fact that $\mathrm{R}^{2}$ values are better in case of Langmuir isotherm than Freundlich and Temkin isotherms implies that the adsorption is monolayer and close to ideal.

$K$ corresponding to equilibrium constant for the adsorption isotherm in the case of ElAwady and is given by,

$$
K=\mathbb{K}_{K}^{\left.(\cdot(\mathbb{B})]^{\frac{1}{y}}\right)}
$$

where $y$ is the number of inhibitor molecules occupying one active site of the adsorbent. Value of $y>1$ implies the formation of multilayers of inhibitor on the surface of metal; value of $y<1$ indicates the formation of monolayer on the metal surface (Niamienet al., 2012; Umasankareswari and Jeyaraj, 2012). y values are less than unity at the two temperatures, an indication of monolayer adsorption. $1 / y$ is the number of surface active sites occupied by one inhibitor molecules (Ayobe et al., 2012), and its values are 2.6709 and 1.3321 at $303 \mathrm{~K}$ and $311 \mathrm{~K}$, respectively.

\section{Conclusion}

This study has demonstrated that Cochlospermum tinctorium methanolic leaves extract has good inhibitive action against the corrosion of mild in $\mathrm{HCl}$ medium. The inhibition action, which was found to be spontaneous and exothermic, was better at lower temperature and can be better modeled by Langmuir isotherm.

\section{References}

Adejo, S. O., Yiase, S. G., Ahile, U. J., Tyohemba, T. G. and Gbertyo, J. A. (2013)Inhibitory effect and adsorption parameters of extract of leaves of Portulaca oleracea of corrosion of aluminium in $\mathrm{H} 2 \mathrm{SO} 4$ solution, Archives of Applied Science Research, 5(1): 25-32.

Adejo, S. O., Ekwenchi, M.M., Momoh, F. and Odiniya, E. O. (2012) Adsorption characterisation of ethanol extract of leaves of Portulaca oleracea as green corrosion inhibitor for corrosion of mild steel in sulphuric acid medium, International Journal of Modern Chemistry, 1(3), 125-134.

Adejo, S. O., Ekwenchi, M.M., Acholo J. P. and Odiniya, E. O. (2010): Thermodynamic and adsorptive properties of ethanol extract of leaves of Sesamum indicum (Benniseed) as eco-friendly inhibitor for the corrosion of mild steel in $\mathrm{H}_{2} \mathrm{SO}_{4}$ medium, The Nigerian Journal of Pure and Applied Sciences, 3: 30 -35 .

Adejo, S. O., Wuana, R.A., Ieave, E. T. and Angba, O. M. (2008) Evaluation of physicochemical and adsorptive properties of adsorbent prepared from Sorghum Bicolor (Guinea-corn) husks, The Nigerian Journal of Pure and Applied Sciences, 1: 19.

Alaneme, K. K. and Olusegun, S. J. (2012) Corrosion inhibition performance of lignin extract of sun flower (Tithoniadiversifolia) on medium carbon low alloy steel immersed in $\mathrm{H} 2 \mathrm{SO} 4$ solution.,Leonardo Journal of Sciences, 20:59-70.

Arora, P. Kumar, S., Sharma, M.K. and Mathur, S. P. (2007): Corrosion inhibition of aluminium by Capparis deciduas in acidic media, e-Journal of Chemistry, 4(4): 450 456.

Atkins, P.W. (1982). Physical Chemistry $2^{\text {nd }}$ ed. W. H. Freeman and Company San Francisco, U.S.A.

Avwiri, O. A. and Igho, F. O. (2003) Inhibitive action of Vernonia amygdalina on the corrosion of aluminium alloys in acidic media, Material Letters, 57(22 - 23): 3705 3711.

Ayobe, E. A, Abaza, S. F., Seleim, S. M. and Ahmed, A. M. (2012) Anodic corrosion of copper in presence of aniline derivatives. Indian Journal of Chemical Technology, 19: 322-330

Bastidas, D. M.; Gomez, P. P.and Cano, E. (2005). The Isotherm Slope: A Criterion for Studying the Adsorption Mechanism of Benzotriazole on Copper in Sulphuric Acid. Revista Metallurgy, 41:98-106. 
Benabdella, M., Benkaddour, M. Hammouti, B. Bendahhou, M. and Aounti, A. (2006) Inhibition of steel corrosion in $3 \mathrm{M} \mathrm{H}_{3} \mathrm{PO}_{4}$ by Artemisia oil, Applied Surface Science,1.252(18): 6212-6217.

Chatterjee, S., Lee, D. S., Lee, M. W. and Woo, S. H. (2009) Enhanced adsorption of congo red from aqueous solutions by chitosan hydrogel beads impregnated with cetyl trimethyl ammonium bromide, Bioresource Technology, Vol. 100 (2009): 2803-2809

Eddy, N. O. and Ebenso, E. E. (2008) Adsorption and inhibitive properties of ethanol extracts of Musa sapeientum peels as a green corrosion inhibitor for the mild steel in $\mathrm{H}_{2} \mathrm{SO}_{4}$ African Journal of Pure and Applied Chemistry. 2 (6): 046-054.

Eddy, N. O., Odoemelam, S. A. and Odiongenyi, A.O.(2008): Ethanol extract of Musa acuminate peel as an eco-friendly inhibitor for the corrosion of mild steel in $\mathrm{H}_{2} \mathrm{SO}_{4}$,Advances in Natural and Applied Sciences, 2 (1): 35-42.

El-Etre, A. Y. (2003) Inhibition of aluminium corrosion using Opuntiaextract,Corrosion Science: $2485-2495$.

Etuk, E.U., Francis, U.U. and Garba, I. (2009) Regenerative action of Cochlospermum tinctoriumaqueous root extract on experimentally induced hepatic damages in rats, African Journal of Biochemistry Research, 3(1): $001-004$

Gunasegaram, G. and Chauhan, L.R. (2004) Ecofriendly inhibitor for corrosion inhibition of mild steel in phosphoric acid medium,Electochimica Acta,Vol. 49(25): 4387-4395.

Hodges, S.A.,Liovensa, X. and Raurel, R.M. (2010) New "eco-friendly" universal inhibitor.Webinars.pcimag.com 25/08/10 11.34am

Jai, J. and Ali, W.S.W. (2008) Palm olein as an ecofriendly corrosion inhibitor, International Conference on Environmental Research and Technology (ICERT 2008)

Khadom, A. A., Yaro A. S. and Abdul A. H. (2010).Adsorption mechanism of benotriazole for corrosion inhibition of coppper-nickel alloy in hydrochloric
acid.Journal of the Chilean Chemical Society,55(1): 150-152.

Niamien, P. M., Trokourey, A. and Sissouma, D. (2012). Copper corrosion inhibition in $1 \mathrm{M}$ $\mathrm{HNO}_{3}$ by 2-thiobenzylbenzimidazole: Adsorption and chemical modelling of the inhibition efficiency. International Journal of Research in Chemistry and Environment, Vol. 2(4): 204-214.

Nair, R. N., Sharma, S., Sharma, I. K., Verma, P. S. and Sharma, A. (2010) Inhibitory efficacy of Piper nigrum Linn, extract on corrosion of AA1100 in HCL. RASAYAN Journal of Chemistry, 3(4): 783-795.

Nnanna, L. A., Obasi, V. U.; Nwadiuko, O. C., Mejeh, K. I. Ekekwe, N. D. and Udensi, S. C. (2012) Inhibition by Newbouldia leavis leaf extract of the corrosion of aluminium in $\mathrm{HCl}$ and $\mathrm{H}_{2} \mathrm{SO}_{4}$ solutions, Archives of Applied Science Research, 4(1): 207-217.

Nergard, C.S., Diallo D., Inngjerdingen K., Michaelsen, T.E., Matsumoto, T., Kiyohara H; Yamada H. and Paulsen, B.S. (2005) Medicinal use of Cochlospermum tinctorium in Mali anti-ulcer, radical scavenging and immunomodulating activities of polymers in the aqueous extract of the roots, Journal of Ethnopharmacology, Vol.96(1 \& 2): $255-269$.

Oguzie, E.E. (2006) Studies on the inhibitive effect of Occimum viridis extract on the acid corrosion of mild steel, Materials Chemistry and Physics,99(2-3): $441-446$.

Okafor, P. C., Ebenso, E. E. and Ekpe, U. J. (2010) Azadirachta Indica extracts as corrosion inhibitor for mild steel in acid medium,International Journal of Electrochemical Sciences, 5: 978-993.

Onen, A.I. and Nwufo, B.T. (2010) Synergistic effect of halide ions on corrosion inhibition of aluminium and mild steel in $\mathrm{H}_{2} \mathrm{SO}_{4}$ solutions using methyl orange, Journal of Chemical Society of Nigeria,35, No. 1: 145156.

Orubite, K.O. and Oforka, N. C.(2008) Inhibition of the corrosion of mild steel in hydrochloric acid solution by the extracts of leaves of Nypa fruticans Wurmb, MaterialsLetters ,58(11): $1768-1772$. 
Orubite-Okorosaye, K. and Oforka, N. C. (2004): Corrosion inhibition of Zinc on $\mathrm{HCl}$ using Nypa fruticans Wurmb extract and 1,5diphenyl carbazone,Journal of Applied Environmental Management, 8(1): 57-61.

Siaka, A. A.; Eddy, N. O.; Idris, S. O.; Muhammad, A.; Elinge, C. M. and Atiku, F. A. (2012). FTIR spectroscopic information on the corrosion inhibitor potentials of ampicillin in $\mathrm{HCl}$ solution,Innovations in Science and Engineering, 2: 41-48.

Togola, A., Diallo, D., Dembele, S. Barsett, H. and Paulsen, B. S. (2005) Ethnopharmacological survey of different uses of seven medicinal plants from Mali (West Africa) in the regions Doila, Kolokani and
Siby,Journal of Ethnobiology and Ethnomedicine. Vol.1 No.7. http://www. ethnobiomed.com/content/1/1/7

Umasankareswari, T. and Jeyaraj, T. (2012). Salicylideneaniline as inhibitor for corrosion of mild steel in $1.0 \mathrm{~N}$ hydrochloric acid. Journal of Chemical and Pharmaceutical Research, 4(7): 34143419.

Umoru, L. E., Fawehinmi, I. A. and Fasasi, A.Y. (2006) Investigation of the inhibitive influence of theobroma Cacao and Cola acuminata leaves extract on the corrosion of a mild steel in sea water,Journal of Applied Sciences Research, 2 (4): 200-209. 